Thorax (1960), 15, 320.

\title{
PULMONARY INFARCTION IN DISORDERS ASSOCIATED WITH THE SICKLE CELL TRAIT
}

\author{
BY \\ S. RAHIMTOOLA, C. J. GOOD, AND P. D. B. DAVIES \\ From the Whittington Hospital, London
}

(RECEIVED FOR PUBLICATION APRIL 5, 1960)

The disorders associated with the sickle cell trait have not, in the past, been seen very often in Britain because they are largely confined to the Negro race. However, increased immigration from the West Indies, where the trait can be found in about $10 \%$ of the Negro population (Tomlinson, 1945), has made the recognition of these diseases more important in this country (Diamond, 1959).

The sickle cell disorders are the result of the inheritance of a dominant gene. This gene determines the presence of an abnormal haemoglobin, haemoglobin $S$. The abnormal haemoglobin in its reduced state is insoluble and readily crystallizes to produce the characteristic distortion of the red cell. In the homozygous individual $75-100 \%$ of red cell haemoglobin will be haemoglobin $\mathrm{S}$, when the severe disease known as sickle cell anaemia develops and death in childhood or early adult life is the usual fate. This is said to occur in about $3 \%$ of all those who carry the gene. If the genetic constitution is heterozygous, sickle cell trait (haemoglobin S) will constitute $25-50 \%$ of the haemoglobin in the red cell and there is usually slight or no clinical disability, except in unusual circumstances, but "manifestations of sickle cell disease such as bone infarction, haematuria, infarction of the spleen and haemolytic anaemia have been recognized with increasing frequency in individuals with sickle cell trait" (Smith and Krevans, 1959). There are other abnormal haemoglobins, such as haemoglobin $C$, which are inherited in the same way, and thalassaemia is the result of the inheritance of a gene which suppresses the formation of normal haemoglobin $A$ and leads to the persistence of the foetal type, haemoglobin $\mathrm{F}$. If any of these traits be combined in a heterozygous subject with the sickle cell trait, then clinical syndromes similar to that of sickle cell anaemia may occur.

Sickling of red cells has two effects; the distorted cells have a short survival time which leads to anaemia of haemolytic type, and they may cause vascular obstruction by blocking small blood vessels or provoking thrombosis in larger vessels because of their increased viscosity.

Sickling develops when haemoglobin $S$ is reduced by deoxygenation and the effect is potentiated by lowering of blood $\mathrm{pH}$. Sickle cells are therefore more common in the venous side of the systemic circulation than the arterial. Sherman (1940) in cases of homozygous SS sickle cell disease found $40-60 \%$ of red cells in the sickled state in blood obtained by venepuncture and only $5-20 \%$ partially sickled in blood drawn from an artery. Sickle cells will be relatively common in the mixed venous blood in the pulmonary arteries, and, as the distortion of the red cell is not an instantaneous response to deoxygenation, the small vessels of the pulmonary circulation may be the first vessels of narrow lumen that the abnormal erythrocytes meet.

Pulmonary arterial obstruction with pulmonary infarction has been described by pathologists as a common post-mortem finding in fatal cases of sickle cell anaemia (Steinberg, 1930; Bauer, 1940), but even in the U.S.A. where the sickle cell trait is common there have been few reports of this condition diagnosed in life (Mallory, 1941 ; Moser and Shea, 1957). In Britain, pulmonary infarction as a complication of the sickle cell trait has not previously been reported.

\section{Case Histories}

CASE 1.-N. L., a male West Indian Negro aged 31, was admitted to the Whittington Hospital on September 24, 1958. He gave a history of five days of severe pleural pain in the left side followed two days later by pleural pain in the right side. He had had a fever but no cough or haemoptysis and no other symptoms. There was no relevant past or family history.

On admission his temperature was $100^{\circ} \mathrm{F}$. He had the physical signs of a pleural effusion in the left chest and signs of consolidation with pleural friction at the right base. There were no other abnormal physical signs and, in particular, no stigmata of sickle cell anaemia. 
Investigations.-He was anaemic and had a leucocytosis. Haemoglobin was 66\% (oxyhaemoglobin method $100 \%=14.8$ g. per $100 \mathrm{ml}$.), R.B.C. 4,685,000 per c.mm., P.C.V. 35\%, M.C.V. 74 cubic microns, M.C.H.C. $33 \%$, W.B.C. 16,400 per c.mm. (neutrophils $70 \%$, eosinophils $8 \%$, lymphocytes $20 \%$, monocytes $2 \%$, reticulocytes $5 \%$ ). Target cells were seen and the red cells showed some polychromasia, E.S.R. $35 \mathrm{~mm}$./hr. (Westergren).

Analysis of the urine showed urobilinogen in normal amounts and no bilirubin. The serum bilirubin level was $0.8 \mathrm{mg}$. per $100 \mathrm{ml}$.

Chest radiographs showed a left pleural effusion with a markedly raised left diaphragm and slightly increased linear markings in the right lower zone. No pathogenic organisms were cultured in the sputum. Pleural aspiration showed a heavily bloodstained fluid, but no pathogenic organisms were cultured. A pleural biopsy showed granulation tissue with large numbers of pleural endothelial cells and some macrophages. The Mantoux test was negative with 1 t.u. but positive with 10 t.u.

At first the diagnosis was thought to be that of pneumonia with pleural effusion. He was treated with penicillin without the fever resolving. The anaemia and the presence of target cells in the blood films (one manifestation of a haemoglobinopathy) had been noted and so paper electrophoresis of haemoglobin was performed a week after admission. This showed haemoglobin S 62\%, haemoglobin C 37.5\%, haemoglobin F $0.5 \%$ (haemoglobins $\mathbf{F}$ and $\mathbf{A}$, identical by paper electrophoresis, were differentiated by the alkali denaturation test). Later, sickling of red cells was demonstrated.

Progress. - The patient improved steadily and the fever resolved by lysis until he was free from symptoms or signs when discharged six weeks after admission. Since then he has been under observation for a year and has kept well.

Three weeks after admission $\mathrm{Hb}$ was $85 \%$, the white blood cell count normal (no eosinophilia) and E.S.R. $23 \mathrm{~mm}$. $/ \mathrm{hr}$. (Westergren). At the time of discharge $\mathrm{Hb}$ was $102 \%$ and E.S.R. $2 \mathrm{~mm} . / \mathrm{hr}$. (Westergren). There has been no recurrence of anaemia.

A fortnight after admission the chest radiograph showed well-marked linear and patchy shadowing in the right lower lobe with a very small pleural effusion; on the left side the pleural shadowing had largely cleared; the diaphragm was slightly lower but was still abnormally raised and there were linear opacities in the left lower lobe (Fig. 1). Thereafter serial films showed gradual clearing on both sides, but, with the development of wide horizontal linear opacities in both lower zones, the left diaphragm gradually descended to the normal position. A year later the chest radiograph was clear.

CAse 2.-A. J., a male West Indian Negro aged 47, was admitted to the Whittington Hospital in September, 1959. He gave a history of severe pleural pain in the left chest for two weeks. He felt feverish but had no other symptoms. He had had malaria in 1942 and pleurisy in August, 1958, which had cleared in two weeks; he had been treated at home for this and no chest radiograph had been taken. There was no relevant family history.

On admission his temperature was $100^{\circ} \mathrm{F}$. The only abnormal physical signs were of a small pleural effusion at the left base, and in particular there were no signs of sickle cell anaemia.

Investigations. - Haemoglobin was $93 \%$, and W.B.C.s were 7,400 per c.mm. The E.S.R. was 95 $\mathrm{mm}$./hr. (Westergren).

Chest radiographs showed a markedly raised left diaphragm and confluent shadowing in the left lower lung field (Fig. 2). The Mantoux reaction was negative with 10 t.u. No sputum could be obtained.

Initially a diagnosis of pneumonia was made and the patient was treated with wide-spectrum antibiotics. He continued to run an intermitent fever. A week after admission he developed severe pleural pain in the right chest, there was audible pleural friction in the right axilla, and the chest radiograph showed linear shadowing in the right lower zone; on the left side there was some clearing with the development of linear shadows in the lower zone. At the same time haemoglobin had fallen to $79 \%$ and the W.B.C. had risen to 17,200 c.mm. (neutrophils $71 \%$, monocytes $11 \%)$.

Further Investigations.-Sickling of red blood cells was demonstrated. Electrophoresis of haemoglobin showed haemoglobin S 50\%, haemoglobin A $49.5 \%$, haemoglobin F $0.5 \%$. The E.S.R. on aerated blood

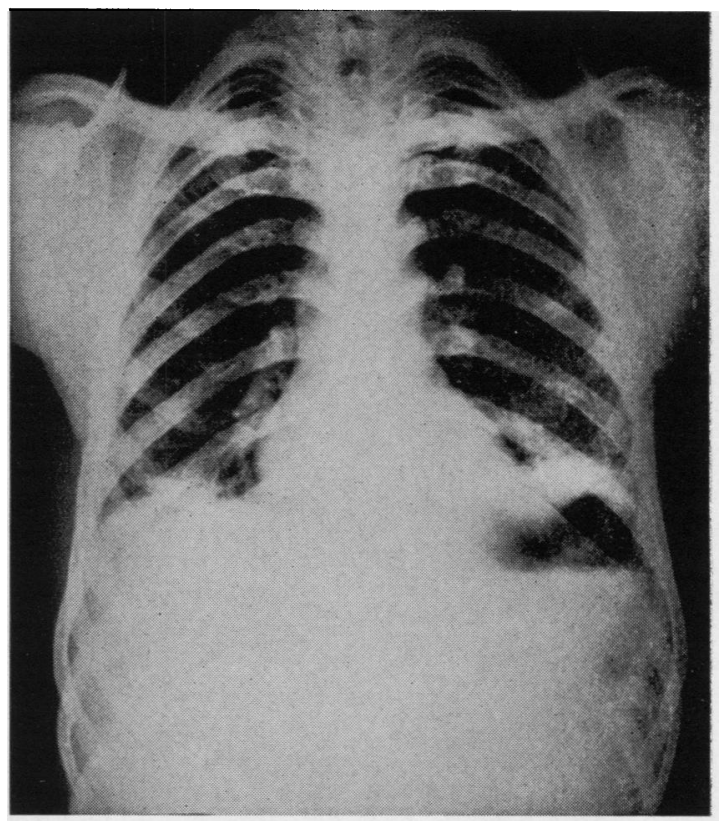

Fig. 1.-N. L. Chest radiograph a fortnight after admission. 


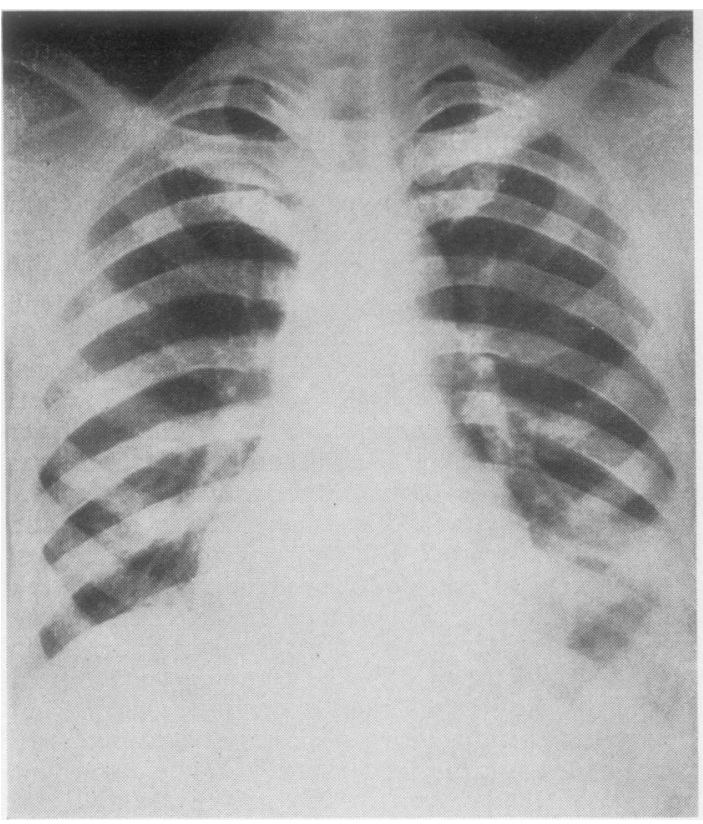

FIG. 2.-A. J. Chest radiograph on admission.

was $94 \mathrm{~mm} . / \mathrm{hr}$, on non-aerated blood $58 \mathrm{~mm} . / \mathrm{hr}$. (Westergren). The blood fiim showed target cells.

No cold agglutinins were found. $Q$ fever and psittacosis complement-fixation tests were negative.

On the tenih day he developed signs of deep venous thrombosis in the left calf. He was then treated by anticoagulants with rapid resolution of fever and other abnormal physical signs. The chest radiograph taken before discharge showed only a slightly raised left diaphragm with minimal linear shadowing in the left lower zone.

CASE 3.-W. B., a male West Indian Negro aged 26. was admitted to the Whittington Hospital in October, 1959. Two weeks earlier he had developed a heavy head cold. This was followed by a productive cough and fever and two days later by pleural pain in the right side. He gave a history of right upper abdominal pain lasting 24 hours in 1956 . There was no relevant family history.

On examination his temperature was $102^{\circ} \mathrm{F}$. The percuss:on note was impaired and breath sounds were diminished at the right base. He had no signs of sickle cell anaemia.

Investigations.-Haemoglobin was $105 \%$, W.B.C. 13,000 c.mm. (89\% neutrophils). The E.S.R. was 70 $\mathrm{mm} . / \mathrm{hr}$. (Westergren).

A chest radiograph showed a slightly raised right diaphragm with a small pleural effusion in the posterior costophrenic angle. Pneumococci were cultured from purulent sputum. Aspiration of the right chest produced a turbid green fluid containing many polymorphs, red blood cells and some endo- thelial cells ; it was sterile on culture. Pleural biopsy showed non-specific chronic inflammation of the pleura. A Mantoux test was negative with 10 t.u. and positive with 100 t.u.

A diagnosis of pleural effusion complicating an aspiration pneumonia was made, and the patient was treated with penicillin. The symptoms rapidly disappeared, the fever resolved by lysis within five days. and a fortnight after admission a chest radiograph was almost completely clear, there being only a small opacity close to the right border of the heart and minimal pleural shadowing along the right costal margin.

On the twenty-second day the patient suddenly developed pleural pain in the left chest. He had no cough or sputum. His temperature rose to $100.2^{\circ} \mathrm{F}$. He was found to have diminished breath sounds at the left base. Two days later he had the signs of a left pleural effusion, and a chest radiograph showed a small left pleural effusion with a raised diaphragm: the right side was now almost normal.

On the thirty-fourth day the patient again developed chest pain without other symptoms. The pain was so severe that he was unable to localize it. His temperature was $104^{\circ} \mathrm{F}$., his pulse rate $120 / \mathrm{min}$. and his respirations were very rapid and shallow. $\mathrm{He}$ now had signs of pleural effusion in both sides of the chest and the radiograph showed bilateral pleural effusions with the diaphragm raised on both sides.

Further Investigations.-Haemoglobin was $90 \%$, W.B.C. $17.700(76 \%$ neutrophils $)$, the E.S.R. 30 $\mathrm{mm}$./hr. (Westergren). No L.E. cells were found, but

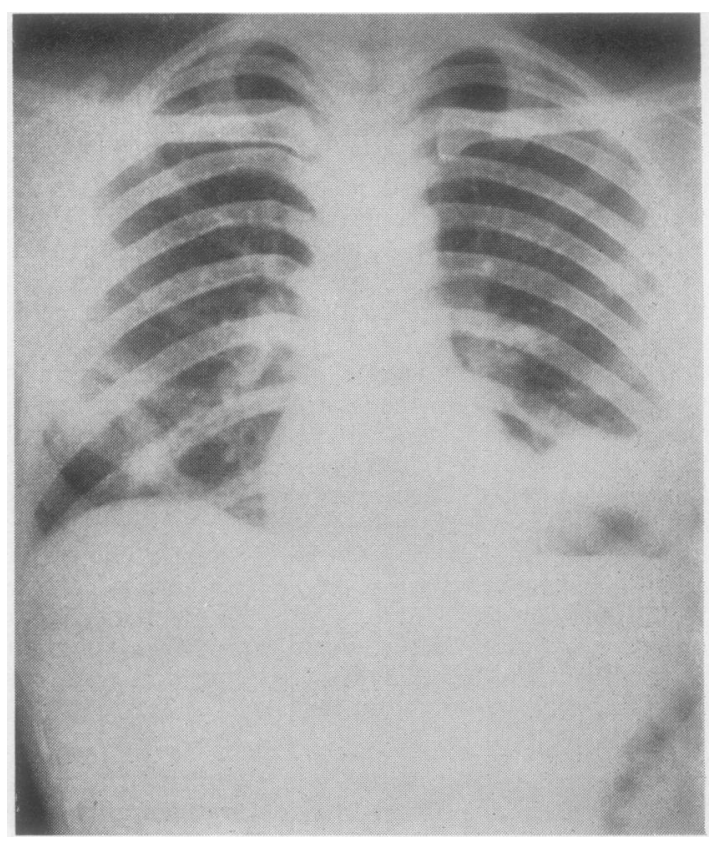

FIG. 3.-W.B. Chest radiograph eight weeks a fter admission. 
sickling of red cells was demonstrated. Paper electrophoresis of haemoglobin showed haemoglobin S 33\%, haemoglobin A $67 \%$. Aspiration of the left chest revealed fluid containing much altered blood.

At the time of the second episode of chest pain three weeks after admission the patient was again treated with penicillin, but the antibiotic did not appear to affect the clinical course of the disease. The third episode was treated with anticoagulants with dramatic effect; the symptoms and signs disappeared and did not recur. A chest radiograph taken eight weeks after admission showed clearing on both sides; on the right side the diaphragm was slightly raised, the right costophrenic angle was obliterated and there was a wide crescentic opacity in the right lower zone ; on the left side also the diaphragm was raised and there was confluent shadowing in the left lower zone (Fig. 3). A left lateral view showed linear shadowing in the left lower lobe with a small pleural effusion.

\section{Discussion}

Sickling of red cells was demonstrated in all three patients. Studies of their abnormal haemoglobins showed their relevant genetic constitutions to be heterozygous. The second and third patients had the sickle cell trait alone ; the first patient had this trait combined with that for abnormal haemoglobin $C$ (haemoglobin S-C disease). These findings do not prove that the illnesses from which the patients suffered were a consequence of intravascular sickling, but no other cause for pulmonary infarction in these previously healthy ambulant men could be found, and there was collateral evidence of activity of the sickling process.

The original illness for which the third patient was admitted was probably a pleurisy complicating pneumonia. The story of a head cold followed by a productive cough and fever and then pleural pain, the recovery of pneumococci from purulent sputum, the polymorphonuclear leucocytosis in the blood, the finding of turbid pleural fluid containing many polymorphs and the rapid response to treatment with penicillin, all fit in well with that diagnosis. However, this patient's subsequent developments and the whole course in the other two patients resemble episodes of pulmonary infarction.

Pulmonary infarction and pneumonitis can be difficult to distinguish, but in all three patients the history of severe pleural pain of sudden onset first on one side and then on the other without other respiratory symptoms is compatible with a diagnosis of pulmonary infarction. Pulmonary opacities, particularly in the lower zones and frequently multiple, with a pleural reaction and a raised diaphragm are the characteristic radiological features of pulmonary infarcts (Figs. 1, 2, and 3 ) and so are thick horizontal linear opacities developing in the later stages (Fig. 3). The haemorrhagic pleural effusions found in the first and third patients are a common accompaniment of an infarct in the lung.

The fever and polymorphonuclear leucocytosis might suggest bacterial pneumonia, but, apart from the third patient's initial illness, the patients did not have cough or sputum, no pathogenic organisms were isolated, and there was no response to antibiotics. The limited virus studies carried out on the second patient and the absence of cold agglutinins gave no evidence of a virus infection and all three patients showed a wellmarked polymorphonuclear leucocytosis. Fever and leucocytosis quite often occur in the acute stage of pulmonary infarction; Wintrobe (1956) states that the leucocytosis and eosinophilia shown by the first and third patients are common features of the crisis of sickle cell disease.

The fall of blood haemoglobin levels at the time of the acute episodes in all three cases suggests that these episodes may have been in the nature of sickle cell crises. The first patient was admitted to hospital with extensive pulmonary lesions when the haemoglobin was $66 \%$; he had no further infarctions, and the haemoglobin rose to $102 \%$ within six weeks. The second patient had a haemoglobin of $93 \%$ on admission, while in hospital he developed pulmonary infarction and a day later the signs of venous thrombosis in the leg, and haemoglobin then fell to $79 \%$. Similarly the third patient's haemoglobin level fell from $105 \%$ on admission to $90 \%$ when he developed pulmonary infarction.

Sickling is known to inhibit rouleaux formation and so to diminish the E.S.R. The higher E.S.R. of aerated than unaerated blood shown by the second patient is said to be diagnostic of sickle cell disease (Winsor and Burch, 1944), and the more severe episodes of these patients' illnesses were characterized by comparatively low sedimentation rates. The first patient was acutely ill and anaemic on admission (Hb 66\%), but the E.S.R. was only $35 \mathrm{~mm}$./hr. (Westergren); whereas the second patient, who was less severely ill and not anaemic on admission (Hb $93 \%$ ), had an E.S.R. of $95 \mathrm{~mm}$. $/ \mathrm{hr}$. The third patient had an E.S.R. of $70 \mathrm{~mm} . / \mathrm{hr}$. on admission, but after he had developed pulmonary infarction and his haemoglobin had fallen $15 \%$, his E.S.R. was only $30 \mathrm{~mm}$. $/ \mathrm{hr}$. 
In none of these patients were sickle cells recognized in ordinary blood films; this is not uncommon in sickle cell disorders because in the process of ordinary examination blood becomes oxygenated and the red cells restored to their normal shape. In each case sickling was demonstrated in a drop of blood sealed under a coverslip on a slide with sodium bisulphite added to speed reduction of haemoglobin by the respiring blood cells. However, special studies have shown that intravascular sickling does occur in those with only the sickle cell trait. Singer (1955) found $3-15 \%$ of red cells in the sickled state in venous blood in haemoglobin S-C disease and about $1 \%$ of red cells in those with haemoglobin SA. Factors which cause anoxia, such as respiratory infections or air travel at high altitudes, can precipitate a crisis in those with only the sickle cell trait (Cooley, Peterson, Engel, and Jernigan, 1954). Moser and Shea (1957) described seven cases of pulmonary infarction with sickle cell disease; two of their patients had only the trait (haemoglobin SA) and one haemoglobin SC; their other patients had sickle cell anaemia (haemoglobin SS).

The second patient developed signs of deep vein thrombosis in the leg; this might suggest that his pulmonary infarctions were embolic in origin. However, his first pulmonary episode preceded the appearance of signs in the leg by three weeks, and his second pulmonary episode occurred 24 hours before the leg signs were detected. The first and third patients had no signs of venous thrombosis in the legs at any time. Though it is commonplace at necropsy to find pulmonary embolism by clots which had formed in lower limb veins without having produced obvious clinical signs in the legs, nevertheless it seems reasonable in our three cases to suggest that the pulmonary infarcts may have been the result of pulmonary arterial thromboses in situ. In none of Moser and Shea's seven cases were signs of venous thrombosis in the legs found.

The second and third patients were treated with phenindione as an anticoagulant. This was tried when the second patient developed signs of venous thrombosis in the leg. Although it has been suggested that anticoagulants will not prevent the thrombotic phenomena of sickle cell disease (Murphy and Shapiro, 1945; Henderson, 1951) and although a suggestion that tricoumacetate ("tromexan") inhibited sickling has not been confirmed, both patients appeared to respond clinically to anticoagulant treatment.

In time these patients may suffer recurrence of pulmonary infarction or develop other manifestations of sickle cell disease. Regular clinical, radiological, and electrocardiographic examinations should be made in case pulmonary hypertension and cor pulmonale should develop due to multiple pulmonary arterial obstruction: this can occur without obvious signs of pulmonary infarction (Yater and Hansmann, 1936).

If there is any sign of further active sickle cell disease then these patients might be prophylactically treated with acetazolamide which theoretically could diminish intravascular sickling. The drug inhibits the action of carbonic anhydrase. Interference with this enzyme's activity in the red cells retards the reduction of haemoglobin (Hilkovitz, 1957).

\section{SUMMARY}

Three cases are described of pulmonary infarction in West Indian Negroes with the sickle cell trait. They are the first reported in Britain.

We are very grateful to Dr. Arnold Bloom, Dr. Wallace Craig, and Dr. T. St. M. Norris of the Whittington Hospital for permission to publish these cases.

\section{REFERENCES}

Allison, A. C. (1954). Brit. med. J., 1, 290.

Bauer, J. (1940). Arch. Surg. (Chicago), 41, 1344.

Cooley, J. C., Peterson, W. L., Engel, C. E., and Jernigan, J. P. (1954). J. Amer. med. Ass., $154,111$.

Diamond, M. P. (1959). Lancet, $2,322$.

Henderson, A. B. (1951). Amer. J. med. Sci., 221, 628.

Hilkovitz, G. (1957). Brit. med. J., 2, 266.

Mallory, T. B. (1941). New Engl. J. Med., $225,626$.

Moser, K. M., and Shea, J. G. (1957). Amer. J. Med., 22, 561.

Murphy, R. C., and Shapiro, S. (1945). Ann. intern. Med., $23,376$.

Sherman, I. J. (1940). Bull. Johns Hopk. Hosp., 67, 309.

Singer, K. (1955). Amer. J. Med., 18, 633.

Singer, K. (1955). Amer. J. Med., 18, 633. Bull. Johns Hopk. Hosp., 104, 17.

Steinberg, B. (1930). Arch. Path. (Chicago), 9, 876.

Tomlinson, W. J. (1945). Amer. J. med. Sci., 209, 181.

Winsor, T., and Burch, G. E. (1944). Ibid., 207, 152.

Wintrobe, M. M. (1956). Clinical Hematology, 4th ed., p. 689. Lea and Febiger, Philadelphia.

Yater, W. M., and Hansmann, G. H. (1936). Amer. J. med. Sci., 191, 474. 